\title{
Interactive Rakuchu Rakugai-zu (Views in and Around Kyoto)
}

\section{$\operatorname{AUTHOR}(\mathrm{S})$ :}

Tosa, Naoko; Nakatsu, Ryohei; Nagao, Makoto; Iwasaki, Naoko; Wada, Tsumiki; Saegusa, Futoshi; Kishigami, Tsuyoshi; Ishikawa, Katsunori; Takaba, Masato; Nishino, Kohei

\section{CITATION:}

Tosa, Naoko ...[et al]. Interactive Rakuchu Rakugai-zu (Views in and Around Kyoto). Culture and Computing 2020, 12215: 415-427

\section{ISSUE DATE:}

2020

URL:

http://hdl.handle.net/2433/261980

\section{RIGHT:}

This is a post-peer-review, pre-copyedit version of an article published in Culture and Computing. The final authenticated version is available online at: http://dx.doi.org/10.1007/978-3-030-50267-6_31.; The full-text file will be made open to the public on 10 July 2021 in accordance with publisher's 'Terms and Conditions for Self-Archiving'.; この 論文は出版社版でありません。引用の際には出版社版をご確認ご利用ください。; This is not the published version.

Please cite only the published version. 


\title{
Interactive Rakuchu Rakugai-zu (Views in and around Kyoto)
}

\author{
Naoko Tosa ${ }^{1}$, Ryohei Nakatsu ${ }^{1}$, Makoto Nagao $^{1}$, Naoko Iwasaki $^{1}$, Tsumiki Wada ${ }^{1}$, \\ Futoshi Saegusa $^{2}$, Tsuyoshi Kishigami ${ }^{2}$, Katsunori Ishikawa ${ }^{2}$, Masato Takaba ${ }^{2}$, \\ Kohei Nishino ${ }^{3}$ \\ ${ }^{1}$ Kyoto University, Kyoto, Japan \\ ${ }^{2}$ TOPPAN PRINTING CO., LTD., Tokyo, Japan \\ ${ }^{3}$ Kyoto Seika University \\ tosa.naoko.5c@kyoto-u.ac.jp,ryohei.nakatsu.7r@kyoto-u.ac.jp, \\ maknag@fm2.seikyou.ne.jp, iwasaki.naoko.4c@kyoto-u.ac.jp, wada.kit@gmail.com, \\ futoshi.saegusa@toppan.co.jp, tsuyoshi.kishigami@toppan.co.jp, \\ katsunori_1.ishikawa@toppan.co.jp, masato.takaba@toppan.co.jp, \\ nishino@cybermanga.com
}

\begin{abstract}
Rakuchu Rakugai-zu is a screen painting illustrating in and around Kyoto created from the beginning of 16th century until 17th century. As in the Funaki Version of Rakuchu Rakugai-zu everyday lives of over 2,000 people in Kyoto are vividly painted, the painting is a good material to learn their customs in early 17th century in Kyoto. However, it is difficult to understand the details of the painting, if background information is not provided. How to document such information and how to provide people such information would be crucial for the future of museums. To cope with this, we are carrying out a project to develop the interactive Rakuchu Rakugai-zu, Funaki Version. Firstly, we digitize the painting with ultra-high resolution. Secondly, using historical books regarding the customs of that era., we identify clothes and behaviors of each person in the painting and linked them to the person in the painting. Thirdly, we develop the technology to provide such information interactively using text or voice. Fourthly, we develop present Funaki Version including various manga characters so that we can compare old and present customs of people. Integrating these contents and technologies we are now developing the interactive Rakuchu Rakugaizu, Funaki Version.
\end{abstract}

Keywords: Rakuchu Rakugai-zu, Funaki Version, Cultural heritage, Interactive museum, Interactive viewing, Online museum.

\section{Introduction}

In order to preserve art works and cultural heritage for everyone to enjoy and for future generations, digitizing and archiving have been often achieved. In particular, with the development of high-definition digital technology, it has become possible to give viewers the feeling as if they are looking at real things [1]. Also, as new devices 
such as high-definition large-screen displays and projectors have emerged, it is now possible to reproduce these contents on a large screen/display. In the past, museums used to make efforts to let people visit with the primary objective of appreciating the real thing, but recently they are actively archiving their own content digitally and open them on the Internet. This would give people the desire to see the real thing, which is expected to increase the number of visitors to museums.

For example, at the National Museum of Japan, high definition digitalization of national treasures and important cultural properties are made public on the Web with the name of eNational Treasures [2]. Since printing companies have advanced high-definition digital technologies, there are many cases where printing companies have partnered with museums to digitize and archive their artworks. For example, Toppan Printing, with the name of Toppan VR, has been showing internal structure of buildings that do not exist anymore or that cannot be opened from the viewpoint of security, work protection, etc. [3]. Also, the Louvre Museum, in partnership with DNP (Dai Nippon Printing), digitizes and archives their artworks and actively open them to public [4].

When people appreciate cultural heritages and artworks, their understanding will be deepened if there is a guide that explains these heritages and artworks. The conventional method for such guidance is to prepare an explanatory document for each artwork. But, as many visitors often stop in front of the explanatory document, often it is difficult to read it. Another method adopted by many museums is that audio explanation of each work is prepared in advance, and the corresponding explanation is provided by voice when a viewer comes in front of the work [1].

However, if a story progression is drawn such as in the case of a painting scroll, or various contents are drawn in a single drawing such as an old city map, the present methods are not efficient enough. Rauchu Rakugai-zu (Views in and around Kyoto) [5] treated in this paper draws various famous spots in Kyoto, that was once the capital of Japan, and it depicts a very large number of people and buildings. As it is impossible to explain each of them in a single explanatory document, it is desirable to provide information regarding to each landmark, individual structure, and also the individual people drawn in the painting. Then viewers can deepen their understanding regarding the customs and so on of the era.

How to document information of a painting with such complex content and how to convey the information to viewers is an important issue. In this paper, we will describe a system that can, by interactively providing explanations about a painting with complex content, let viewers understand it well.

This paper is organized as follows. Chapter 2 explains related papers. Chapter 3 explains what the Rakuchu Rakugai-zu and its Funaki Version are. Chapter 4 describes in detail the interactive Rakuchu Rakugai-zu Funaki Version, that can interactively provide the viewer with its contents, including the concept, the system configuration, and the content of each part consisting the system. Chapter 5 describes the exhibit of the developed system. Finally, the conclusion is given in Chapter 6. 


\section{$2 \quad$ Related Works}

There is an opinion that artworks and cultural heritages should withstand appreciation well even without explanation. However, for a deeper understanding, it is better to know culture and art history of each country regarding these works. For example, modern abstract paintings cannot be easily understood without knowing the history of Western art. Therefore, it is more convenient to have explanations and guidance for understanding artworks and cultural heritages. Some of the research to realize the understanding and appreciation of artworks and cultural heritages easier are as follows.

\subsection{Virtual Museum}

In a virtual museum a 2D or 3D model of a museum is developed and viewers can appreciate artworks by freely moving around in the virtual museum. One good example is the virtual Louvre museum in which the interior of the Louvre museum is prepared as a panoramic image, and a viewer can freely walk around the museum to appreciate each artwork [4]. It is well done as a virtual museum, but has the disadvantage that the descriptions of the exhibits are simple and easy to get bored. A lot of research has been conducted on the design of virtual museums, such as changing the explanation for each individual in order to prevent viewers from getting bored [6] [7].

\subsection{Interactive Museum}

For virtual museums, even in actual museums, conventionally, explanations have always been fixed, and research has been conducted such as changing explanations in accordance with the knowledge of visitors and selecting exhibits to be explained according to their preferences [8-13]. One direction is to make a smartphone of a viewer as a guide by downloading an application to the smartphone. In these studies, it is important how to know the visitor's preference and degree of knowledge.

In addition, instead of tablets and smartphones, research is being conducted to make robots, especially a humanoid robot, act as a guiding agent. It is considered effective to use a humanoid robot as a guide, since humans are easy to feel familiar with a humanoid robot. However, since it is necessary for such robots to perform human interaction with humans through natural language and gestures, research on such human-robot interactions is actively conducted [14] [15] [16].

\section{Rakuchu Rakugai-zu and Its Funaki Version}

\subsection{Rakuchu Rakugai-zu}

Kyoto was the capital of Japan during the Heian period (794-1185), and after the transfer of political power from the emperor to the samurai, it continued to be the cultural center as the emperor lived there until the end of the Edo period, and is still the center of Japanese culture. The Rakuchu Rakugai-zu [5] is a painting depicting the 
scenery and customs of the city (Rakuchu) and the suburbs (Rakugai) of Kyoto, which cultural, historical, and academic values have been highly valued. Two of them have been designated as national treasures and five of them designated as important cultural properties. They were produced from the early 16th century, when groups of warriors from all over Japan fought for supremacy, to the Edo period, when the political control by the Tokugawa Shogunate was established. Among the existing ones, 30 to 40 works are well preserved. Figure 1 shows an example of Funaki Version, which is preserved as two sets (left wing and right wing) of Byobu (folding screen) [20].

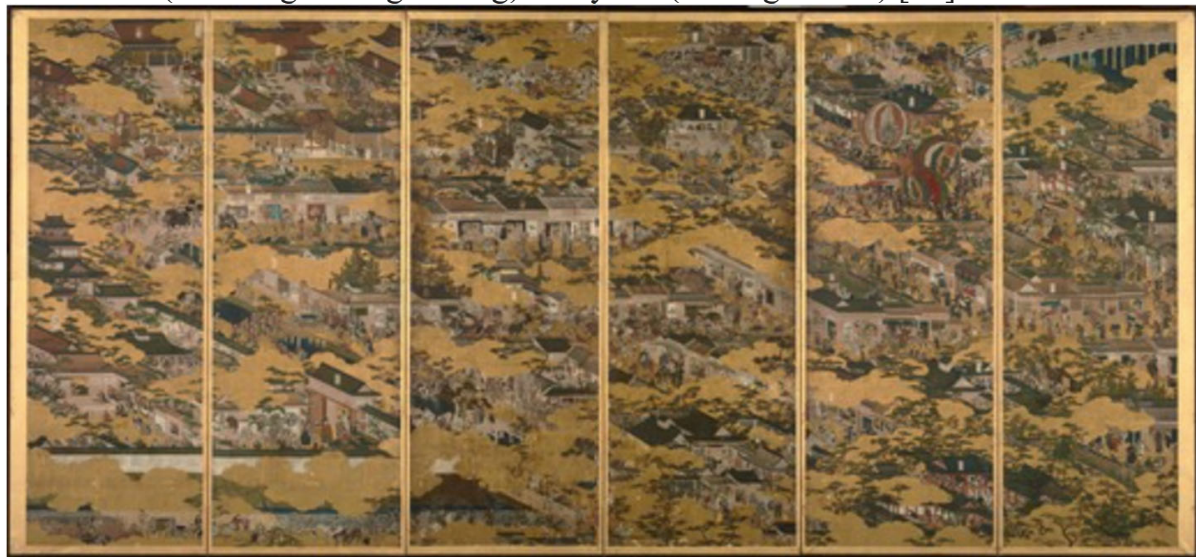

(a) Left wing

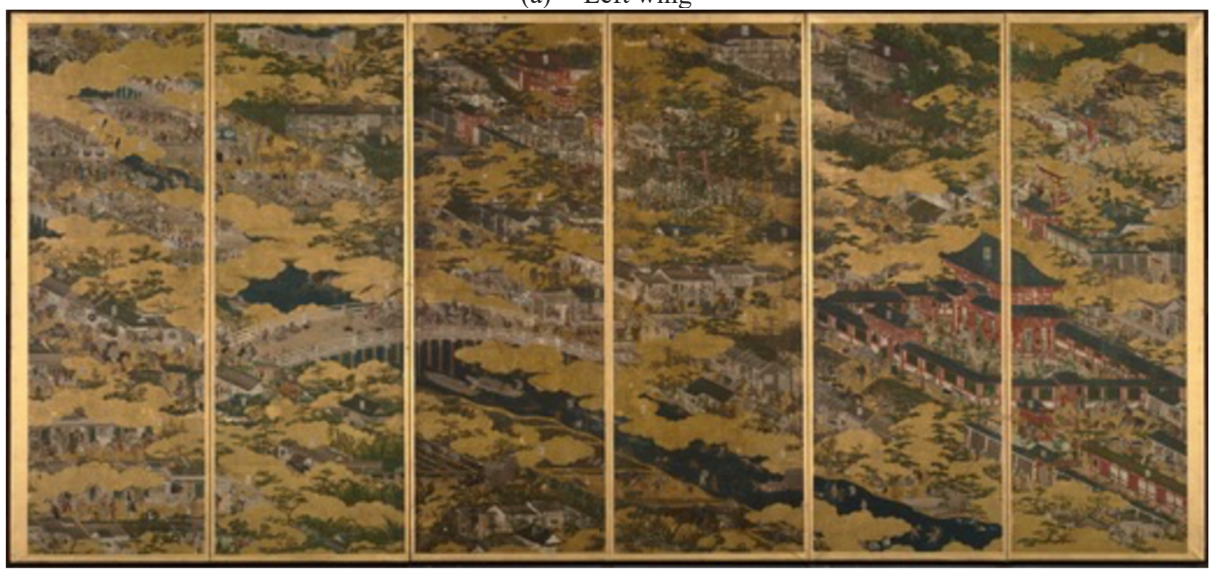

(b) Right wing

Fig. 1. Rakuchu Rakugai-zu Funaki Version

The era in which the Funaki Version was drawn is a politically unstable one in Japan. However, as mentioned above, Kyoto has been the center of Japanese culture for a long time and people used to enjoy their stable lives. Also, Kyoto have attracted many tourists from all over Japan. Especially, the desire to visit Kyoto was high among people living in rural areas. Therefore, Rakuchu Rakugai-zu made people aware of the center of Japanese culture and also served as a tourist guide. 
More than 2,000 people are drawn on Rakuchu Rakugai-zu, and their personality, occupation, clothing, hairstyle, etc. are important research subjects. It is general that the Rakuchu Rakugai-zu is drawn as the two folding screens; east side of Kyoto on the right wing, and west side of Kyoto on the left as a bird's-eye view. In the early Rakuchu Rakugai-zu the landscape of the Sengoku-jidai (Warring States period) [18] is drawn. In the right half the down town of Kyoto including the Kamo River, the Gion Shrine, and Higashiyama areas are drawn. The left half includes famous places such as the samurai residences, the Funaokayama Hill, the Kitano Tenmangu Shrine, etc. In the Edo era, many Rakuchu Rakugai-zu drew the Kouho-ji Temple, that was famous by its big Buddha stature, on the right wing and the Nijo Castle on the left wing.

\subsection{Rakuchu Rakugai-zu Funaki Version}

Rakuchu Rakugai-zu Funaki Version (hereafter the Funaki Version) is one of many Rakuchu Rakugai-zu. More than 2,000 of people are drawn in it in extremely detailed and dynamic way, and the daily lives and manners of the people of Kyoto are drawn well.

It is said that the Funaki Version was painted by a painter Iwasa Matabei, and the time of painting is around 1614. It is the time when political power in Japan was being transferred from the Toyotomi administration established by Toyotomi Hideyoshi, who achieved national reunification, to the Tokugawa government established by Tokugawa Ieyasu. As Toyotomi family will be destroyed in the two battles called the "1614 and 1615 Osaka Battles," what is depicted in the Funaki Version is the scenery of Kyoto just before the battle. On the left side of the left wing drawing is Nijo Castle, which shows off the authority of the Tokugawa Shogunate. At the same time, however, as opposed to it, the Hokoji Buddha built by the Toyotomi family boasts the dignity at the right end of the right wing. It shows that the power of the family is still great. Under such historical background, a group of samurai warriors who hurry up and a scene of tension with people fighting with a sword or a spear is also depicted. However, despite of such a political situation, it looks that everyday life of people in Kyoto is normal and usual. And the city is filled with the energy of such people.
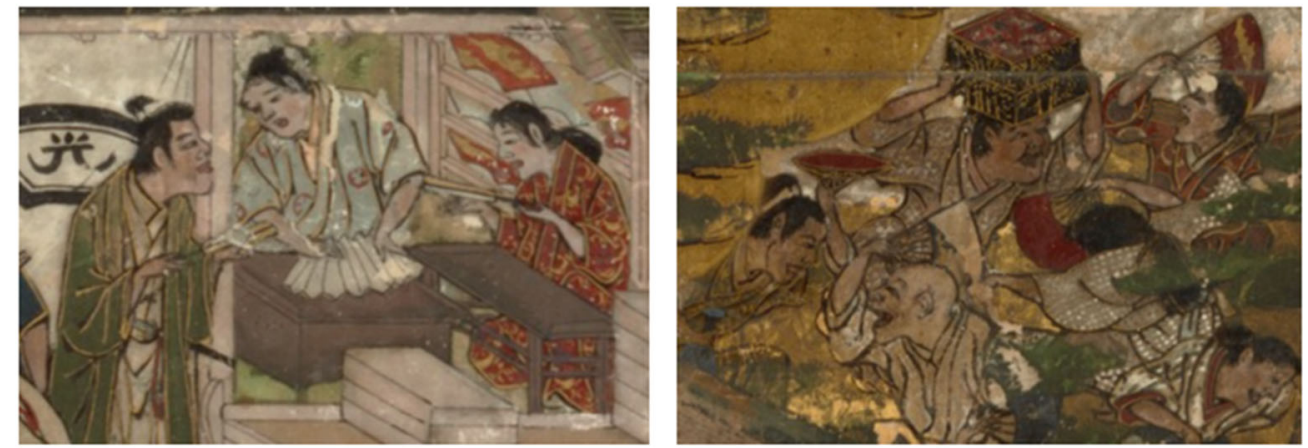

Fig. 2. Zoom-up view of the Rakuchu Rakugai-zu Funaki Version 
Iwasa Matabei is an excellent painter for drawing people's lively expressions and movements. While viewers watch the drawing from a distant position, it is difficult to notice this, but when they approach the drawing, the lively expressions and actions of people in the drawing become distinctive. By looking at the details of the Funaki Version, viewers would be interested in the lifestyles and customs of the people of Kyoto in the early 17 th century. Figure 2 shows several examples of enlarged views of persons drawn in the Funaki Version.

\section{$4 \quad$ Interactive Rakuchu Rakugai-zu}

\subsection{Concept}

In the Funaki Version, the clothes, actions and expressions of over 2,000 people are drawn in detail and they are very intriguing. Viewers would have questions as to what kind of occupation and status they are, what kind of clothes they are wearing, and what they are doing now. By knowing these things, viewers can know the lives of people at that time, and they can know what the daily lives of these people were during the unstable political situation at that time. Furthermore, from the standpoint of studying society and customs at that time, it is required that the system can answer questions such as what kind of occupation people are engaged in and what is the proportion of each occupation.

Since the knowledge that viewers want to know is different from person to person, it is necessary for the system to be able to interactively give such information. Based on this consideration, we are developing an interactive system of the Funaki Version.

After completion, we aim to open the platform on the Internet so that various people can search for information and freely exchange information, and so on.

\subsection{Digital Funaki Version}

In order to develop an interactive Funaki Version, firstly it is necessary to digitize and archive the original Funaki Version. The original Funaki Version is currently stored at the Tokyo National Museum. Toppan Printing Co., Ltd., to which several of the authors belong, cooperates with the Tokyo National Museum and has developed a system that converts the Funaki Version into high-definition digital data with 2.21 billion pixels. The system has the function of moving the viewpoint to any position by a mouth or a finger, and zooming-in with an arbitrary size. Although the size of each person drawn in the original drawing is at most a few centimeters, when viewers zoom it up about 100 times and watch it on a big screen of several hundred inches, they can watch very detailed view of people in the drawing including their face expressions, closes, action, etc. as shown in Fig. 2. 


\subsection{Database}

The aim of this interactive system is to realize the function to answer viewers' various questions regarding persons and buildings drawn in the Funaki Version. For that purpose, we have designed and developed the architecture of the database as follows.

\section{Database structure}

The painting is divided into sets of appropriate square boxes and systematic 2D address was given to each of the boxes. Also, multiple names were given to each box regarding the place, object, and event such as the Shijo Bridge, the Shijo Street, the Gion Festival, etc. These multiple names are used to link each place/object/event and its position.

\section{Contents of the database regarding place/object/event}

Regarding each of places and objects such information as shrine/temple/house, vehicle, goods, their meanings, etc. was prepared and given. For event name, such information as content of event, season, etc. was given.

\section{Contents of the database regarding person}

For each person, viewers would be interested in such information as the kind of occupation or position of the person, what the person is wearing, and what he/she is doing. For that purpose, we prepared data of the following structure for each person.

Tile number, location, gender, occupation, clothing, hat, hairstyle, mustache/beard, belongings, actions, and comments.

Such information was prepared and given to each of more than 2,000 persons drawn in the Funaki Version. Table 1 shows a part of the database regarding person.

Table 1. Example of the database

\begin{tabular}{|c|c|c|c|c|c|c|c|c|c|c|}
\hline Tile number & Place & Gender & Occupation & Clothing & Hat & Hairstyle & \begin{tabular}{|l} 
Mustache/ \\
Beard
\end{tabular} & Belongings & Actions & Comments \\
\hline U3-1-1 & Kiyomizu Temple & Male & Samurai & $\begin{array}{l}\text { Men's } \\
\text { Kimono }\end{array}$ & Straw hat & Invisible & Mustache & None & $\begin{array}{l}\text { Standing } \\
\text { and } \\
\text { waching }\end{array}$ & \\
\hline U3-1-1 & Kiyomizu Temple & Male & Monk & \begin{tabular}{|l} 
Clerical \\
dress
\end{tabular} & None & Bold & None & None & $\begin{array}{l}\text { Sitting and } \\
\text { sightseeing }\end{array}$ & \\
\hline U3-1-1 & Kiyomizu Temple & Female & Unknown & \begin{tabular}{|l|} 
Woman's \\
Kimono
\end{tabular} & None & $\begin{array}{l}\text { Binded at } \\
\text { the back }\end{array}$ & None & None & $\begin{array}{l}\text { Standing } \\
\text { and talking }\end{array}$ & \\
\hline U3-1-4 & Gion Temple & Male & Samurai & $\begin{array}{l}\text { Kimono and } \\
\text { hakama }\end{array}$ & None & \begin{tabular}{|l|}
$\begin{array}{l}\text { Samurai } \\
\text { style }\end{array}$ \\
\end{tabular} & Mustache & Sword & Walking & \\
\hline U3-1-4 & Gion Temple & Male & Samurai & $\begin{array}{l}\text { Kimono and } \\
\text { hakama }\end{array}$ & Straw hat & $\begin{array}{l}\text { Samurai } \\
\text { style }\end{array}$ & None & $\begin{array}{l}\text { Sword and } \\
\text { fan }\end{array}$ & $\begin{array}{l}\text { Talking } \\
\text { while } \\
\text { walking }\end{array}$ & \\
\hline U3-1-4 & Gion Temple & Female & Unknown & $\begin{array}{l}\text { Woman's } \\
\text { Kimono }\end{array}$ & None & $\begin{array}{l}\text { Natural } \\
\text { style }\end{array}$ & None & $\begin{array}{l}\text { Bottle of } \\
\text { sake }\end{array}$ & $\begin{array}{l}\text { Sittng and } \\
\text { drinking }\end{array}$ & \\
\hline U3-1-6 & Tokuhara Temple & Female & Shop staff & \begin{tabular}{|l} 
Woman's \\
Kimono
\end{tabular} & None & \begin{tabular}{|l} 
Natural \\
style
\end{tabular} & None & Mortar & $\begin{array}{l}\text { Sitting and } \\
\text { cooking }\end{array}$ & \\
\hline U3-1-6 & Tokuhara Temple & Female & Shop staff & $\begin{array}{l}\text { Woman's } \\
\text { Kimono }\end{array}$ & None & & None & None & $\begin{array}{l}\text { Sitting and } \\
\text { watching }\end{array}$ & \\
\hline$\ldots$ & $\ldots$ & $\ldots$ & $\ldots$ & $\ldots$ & $\ldots$ & $\ldots$ & $\ldots$ & $\ldots$ & $\ldots$ & \\
\hline & & & & & & & & & & \\
\hline
\end{tabular}

\section{How to get information}


It is a time consuming work to get various information shown in Table 1 for more than 2,000 persons drawn in the Funaki Version. We have asked several Kyoto University researchers and students studying Japanese history to do this. They identified such information based on their expertise and when it is difficult for them to do this, they identified such information by referring to various history books stored in the Kyoto University Library. Also, we have carried out several interviews with persons whose family live long time in Kyoto and know various old stories about Kyoto.

\subsection{Dialogue function}

The above database structure makes it possible for the system to do the following dialogue based interaction.

(1) By indicating a person or an object in the painting shown on a tablet PC, viewers can ask what it is, what it is doing, whether there are other similar persons, and so on.

- Pointing of a position: pin pointing and area pointing are possible.

- Information display: If the indicated object has information, an appropriate natural language based answer is composed and is displayed on a pop-up window.

- Search for similar things: If the indicated thing has a description, it can search other ones with the same descriptions and display their images.

(2) If a viewer asks a question by text, the system searches and displays corresponding object with a zoom-in view. (So far, the system accepts only text input, but speech input will become possible soon.)

- Question on place: Gosho (Imperial house), Gojo Bridge, Shijo Street, etc.

- Question on action: festival, prayer, rice planting, fight, etc.

- Question on types of goods: cattle, bells, swords, etc.

- Combination of these questions: example: "Where is vehicle being drawn at Gion Festival?"

(3) By combining (1) and (2), viewers can continue dialogue with the system.

In order to be able to achieve the above interaction, a dialogue system shown in Fig. 3 was developed.

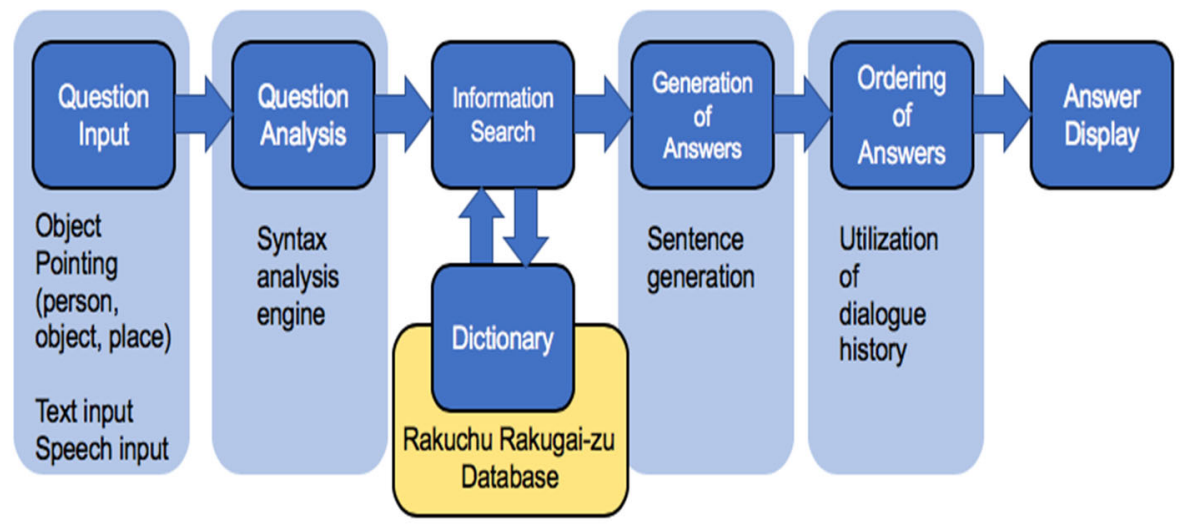

Fig. 3. Block Diagram of the Dialogue System 


\subsection{Present Funaki Version}

When viewers look at the Funaki Version, they will be interested in the fact that the everyday lives of people are vividly depicted in almost every part of the drawing, and they will also be interested in what these places look now. When we exhibited the system, which will be described in Chapter 5, we received many questions and comments such as "What does this place in the Funaki Version look now?" or "It would be great if I could compare the time of the Funaki Version and present." In order to meet such hopes, we decided to produce a present version of Funaki Version.

Firstly, among various places drawn in the original Funaki Version, we have identified several places where viewers would be particularly interested such as the Shijo Street, the Gosho (emperor house), etc. In addition, we have decided to draw several representative events, which could survive long history and remain until today, such as the Gion Festival, to compare them with those drawn in the Funaki Version. Furthermore, in order to compare the appearance/dress of people of those days depicted in the Funaki Version with those of the present people, we also have decided to draw present people. Because persons in the Funaki Version are drawn in a deformation way regarding to their expressions/actions, which actually attracts our interest, it is better to draw a cartoon based character rather than to draw a present person as a realistic person. Based on this consideration, we have asked students of Manga (comic) Department of Kyoto Seika University to create such characters.

Figure 4 shows characters, vehicles, events of the present version superimposed on the original Funaki Version.

In Fig.4 (a), to illustrate the difference between the Funaki Version's era and the present, Shinkansen (Japanese bullet train) and the Gojo Street, where many cars come and go, are drawn. Also, in Fig.4 (b), vehicles used in the Gion Festival, that are moving along the Kawaramachi Street, are drawn.

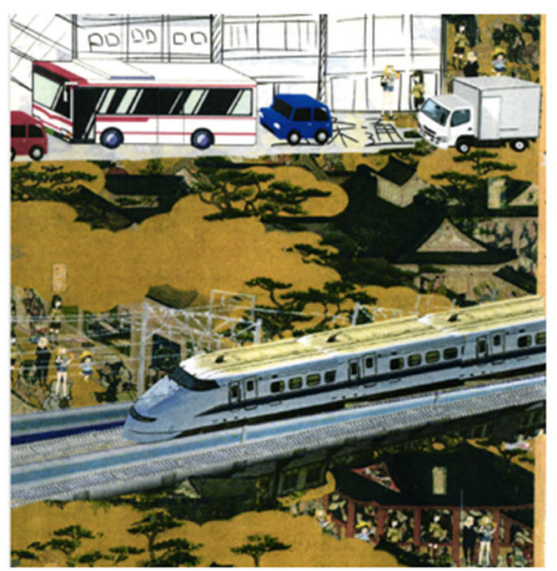

(a) Shinkansen (bullet train) and Gojo street

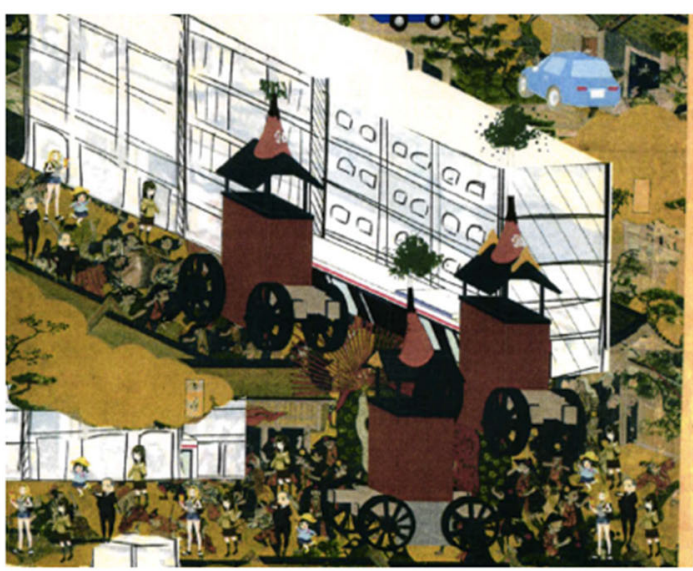

(b) Kawaramachi Street and Gion Festival

Fig. 4. Present Funaki Version overlapped on the original version 
The followings were recognized through the development of the present Funaki Version.

(1) Modern buildings are too large compared to the houses/buildings at the time of the Funaki Version and therefore, they would not match when superimposed on the original version. Therefore, it is better to limit the drawing of modern buildings only to such characteristic buildings as the Kyoto Tower. Also, it is not relevant to strictly consider the size ratio.

(2) It is better to use modern characters not only simply but also more aggressively when putting them in the original Funaki Version. There are several ways to realize this. For example, it is relevant to draw as if modern characters are participating in events such as Hanami (cherry blossom viewing) and the Gion Festival in the original Funaki Version. Another idea is that a viewer manipulates the modern character by itself in the original Funaki Version and let it speak to persons of the original version. (In other words, modern characters would play the role of "player characters" in a game). Anyway, we plan to decide an appropriate way while exhibiting the system and listening to viewers' comments.

\section{Exhibition}

The above system is currently under development. But it is important to obtain various opinions from viewers by exhibiting the system even at the development stage, and to feedback the obtained opinions for future system development. As a part of this effort, we exhibited the system at an international conference called the Art Science International Symposium held at Kyoto University in March 2019 [21], and the system was well appreciated by researchers and the general public. Figure 5 shows the scenes of the exhibition.

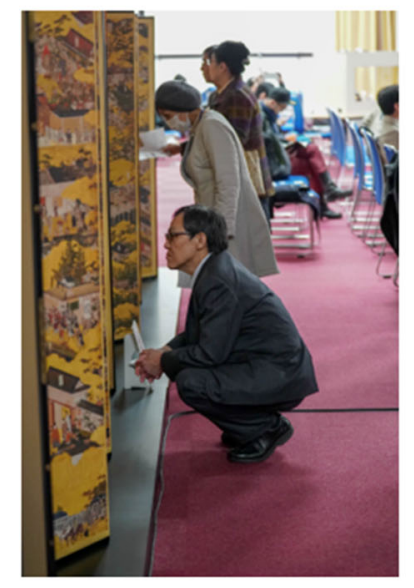

(a) Exhibition of the original Rakuchu Rakugai-zu.

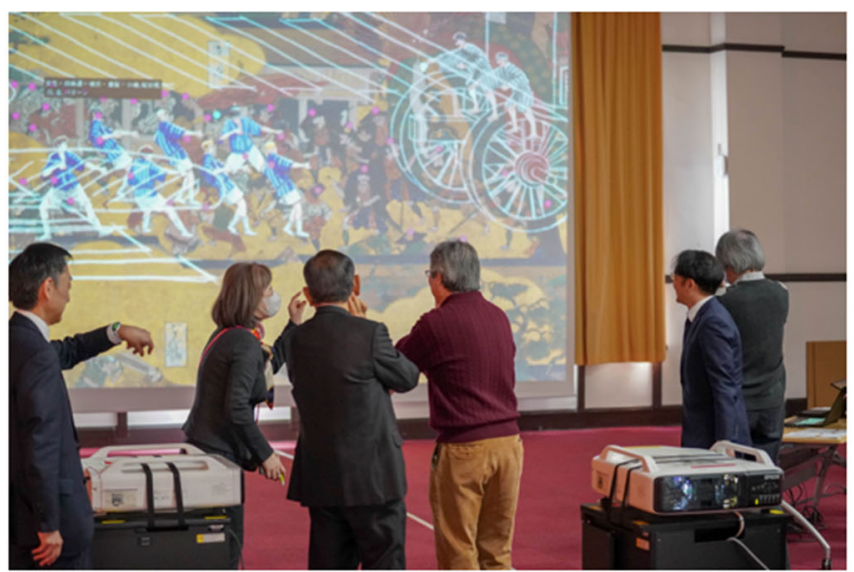

(b) Exhibition of the developed interactive system.

Fig. 5. Exhibition of the original and interactive Rakuchu Rakugai-zu. 
Figure 5 (a) shows a scene of exhibiting a full size high-definition copy of the original Rakuchu Rakugai-zu. Many people enjoyed the appreciation of the original version with ultra-high definition. Figure 5 (b) is a scene in which the interactive system is displayed. A tablet PC was provided for a viewer, which has the function of allowing the viewer to freely move to an arbitrary place on the map and zoom-in or out. Also, when a specific person in the drawing is tapped, information on the person is displayed in a separate window. Furthermore, by displaying the screen of the tablet PC on a large screen using a projector, how the interaction is going on could be appreciated by other people. We received various opinions from the viewers, and now are analyzing them for the future development.

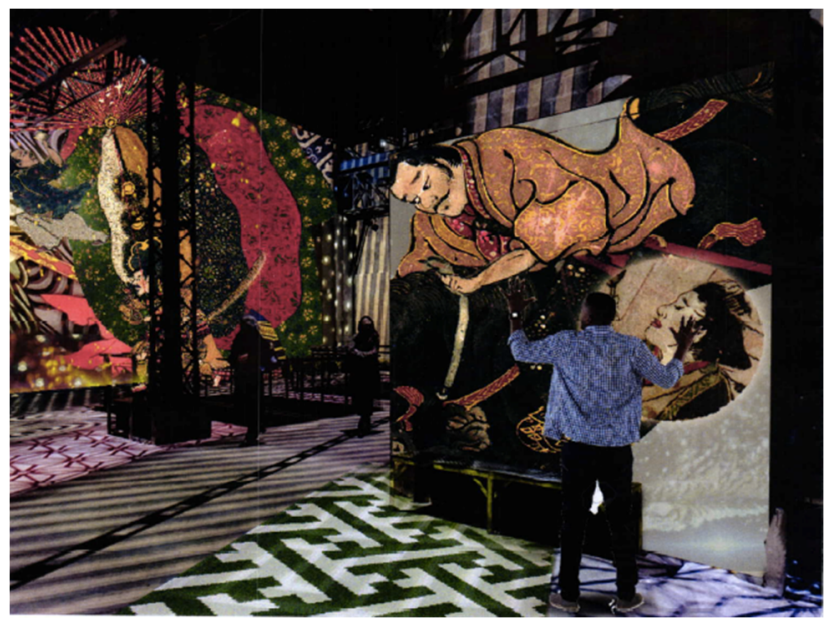

Fig. 6. VR Exhibition of the Interactive Funaki Version.

In addition, since a VR type exhibition would give the immersive impression of actually entering into the world of the Funaki Version, VR exhibition of the interactive Funaki Version would be very effective. We are planning to carry out such VR exhibition as shown in Fig. 6.

\section{Conclusion}

In the 16th and 17th centuries in Japan, various Rakuchu Rakugai-zu (Views in and around Kyoto) were created as drawings depicting the city and the surrounding areas of Kyoto. Among them the Funaki Version is well-known, as it draws more than 2,000 persons, each of whom is drawn vividly. We are developing the interactive Rakuchu Rakugai-zu Funaki Version, with the purpose of providing viewers better understanding of the original Funaki Version by interactively providing information on persons, buildings, famous places, and so on.

In this paper, we first explained what the Rakuchu Rakugai-zu is and described the features of the well-known Rakuchu Rakugai-zu Funaki Version. Then, we described the details of the interactive Funaki Version, focusing its database, dialogue function, 
and its present version to be overlapped on the original one. We also described our experience of exhibiting the system and how it attracted the interest of many people.

This system is now being improved based on the viewers' comments and opinions obtained at the exhibition. At the stage of completion, we aim it to be open on the Internet and also aim it to become an online intellectual space where many people can gather and exchange opinions.

\section{Reference}

1. Bay, H., Fasel, B., Gool, L. C., "Interactive Museum Guide," Proceedings of UbiComp 2005, (2005).

2. http://www.emuseum.jp/top?d_lang=en

3. http://www.toppan-vr.jp/mt/en/

4. http://www.dnp.co.jp/eng/

5. Christie's, "A Magnificent Rakuchu Rakugai Screen New York October 16, 1990," Christie's (1990).

6. Haskins, E., "Between Archive and Participation: Public Memory in a Digital Age," Rhetoric Society Quarterly, Vol.37, pp.401-422 (2007).

7. Sylaiou, S., et al., "Exploring the relationship between presence and enjoyment in a virtual museum," International Journal of Human-Computer Studies, Vol.68, No.5, pp.243-253 (2010),

8. Ciolfi, L, Bannon, L. J., "Designing Interactive Museum Exhibits: Enhancing visitor curiosity through augmented artefacts," Proceedings of ECCE11 (2001).

9. Hindmarsh, J., Heath, C., Lehn, D. V., Cleverly, J., "Creating Assemblies in Public Environments: Social Interactive, Interactive Exhibits and CSCW," Computer Supported Cooperative Work, Vol.14, pp.1-41 (2005).

10. Caultom, T., "Hands-On Exhibitions: Managing Interactive Museums and Science Centres," Routledge, London (2006).

11. Sandifer, C., "Technological Novelty and Open-Endedness: Two Characteristics of Interactive Exhibits That Contribute to the Holding of Visitor Attention in a Science Museum," Journal of Research in Science Teaching Vol.40, No.2, pp.121-137 (2003).

12. Bitgood, S., "Suggested Guidelines for Designing Interactive Exhibits," Visitor Behavior, Vol.VI, No.4, pp.4-11 (1991).

13. Hornecker, E., Stifter, M., "Learning from Interactive Museum Installations About Interaction Design for Public Settings," Proceedings of OZCHI 2006, pp.1-8 (2006).

14. Burgard, W., et al., "The Interactive Museum Tour-Guide Robot," Proceedings of AAAI-98 (1998).

15. Shiomi, M., Kanda,T., Ishiguro, H., Hagita, H., "Interactive Humanoid Robots for a Science Museum," Proceedings of HRI'06, pp.305-312 (2006).

16. Thrun, S., et al., "Probabilistic Algorithmas and the Interactive Museum Tour-Guide Robot Minerva," The International Journal of Robotics Research, Vol.19, No.11, pp.972-999 $(2,000)$.

17. Mason, R., Caiger, J., "A History of Japan,” Tuttle Publishing (2004).

18. Sengoku period https://en.wikipedia.org/wiki/Sengoku_period

19. Chaplin, D., "Sengoku Jidai, Nobunaga, Hideyoshi, and Ieyasu: Three Unifiers of Japan

20. https://en.wikipedia.org/wiki/Byōbu

21. http://art.gsais.kyoto-u.ac.jp/index-en.html 